
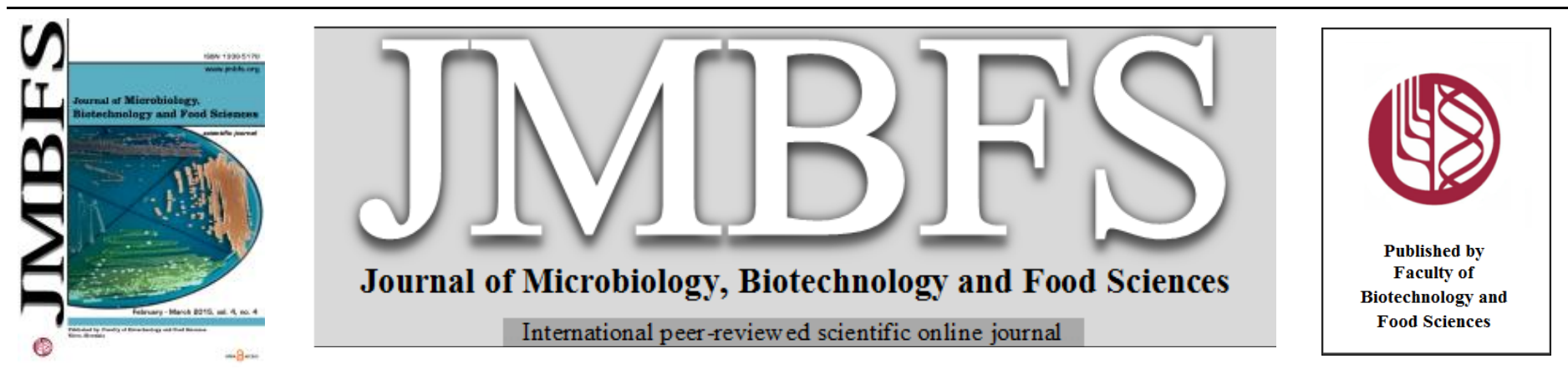

\title{
ANTI - SHIGELLA DYSENTERIAE ACTIVITY BY PROBIOTIC LACTIC ACID BACTERIA (PEDIOCOCCUS PENTOSACEUS); AN IN VITRO STUDY
}

\author{
Srividya D. ${ }^{l}$, Chandra Prakash S. V. ${ }^{l}$, Shylaja M. Dharmesh ${ }^{l}$, Renu Agrawal ${ }^{2}$ \\ Address(es): Shylaja M Dharmesh, \\ ${ }^{1}$ Department of Biochemistry and Nutrition, CSIR-Central Food Technological Research Institute, Mysore - 570020, INDIA. \\ ${ }^{2}$ Department of Food Microbiology, CSIR-Central Food Technological Research Institute, Mysore - 570020, INDIA.
}

*Corresponding author: cancerbiolab@gmail.com

doi: $10.15414 / j m b f s .2015 .4 .4 .317-320$

\section{ARTICLE INFO}

Received 17. 10. 2014

Revised 17. 11. 2014

Accepted 5. 12. 2014

Published 1. 2. 2015

Regular article

OPEN $\partial_{\text {ACCESS }}$

\begin{abstract}
Shigellosis caused by Shigella is prevalent throughout the world with approximately 164.7 million cases, of which 163.2 million are in developing countries as per the World Health Organization report. In the current study the effect of a known Probiotic Lactic acid Bacteria (PLB) Pediococcus pentosaceus, a previously reported strain of PLB from our laboratory on gastroenteric pathogen - Shigella dysenteriae was studied and its mode of action was established. In agar diffusion tests PLB lysate showed larger inhibition zones of $S$. dysenteriae than a known Shigella susceptible antibiotic ampicillin which shows a better potentiality of PLB lysate over standard antibiotic. Further the effect of PLB lysate on Shigella dysenteriae lysis was confirmed by electrophoretic and microscopic study. PLB lysate at $250 \mu \mathrm{g} / \mathrm{mL}$ protein concentration inhibited $\sim 70 \%$ of Shigella dysenteriae growth in vitro. A significant protection was observed against the cellular damage caused by Shigella dysenteriae lysate. Red blood cells and buccal cells protection against the lysis induced by Shigella dysenteriae lysate substantiated the cytoprotective role of PLB, thus PLB can be an effective natural agent against Shigella
\end{abstract} mediated infection.

Keywords: Shigellosis, anti-Shigella activity, Probiotic Lactic acid Bacteria (PLB), Cellular damage and protection

\section{INTRODUCTION}

Shigellosis is an intestinal disease and a serious health problem in north-eastern parts of India and other developing countries in world (Swapan, 2005; Reema $\boldsymbol{e t}$ al., 2013). It is caused by Shigella, being epidemic it attained multi drug resistance. Shigella dysenteriae is one of the prominent infectious strains out of Shigella species. A report states Shigella dysenteriae showed resistance to Chloramphenicol $(80 \%)$, Tetracycline (100\%), Co-trimoxazole (100\%), Nalidixic acid $(100 \%)$ and Ciprofloxacin (100\%) (Datta et al., 2003; Deen et al., 2004; Alam and Shrish, 2006). S. dysenteriae causes Shigellosis along with inflammatory diarrhea and dysentery. The symptoms of Shigellosis include sepsis, dehydration, encephalopathy, intestinal perforation, toxic megacolon, and pneumonia. In few cases it may leads to hemolytic uremic syndrome which is a life threating systemic disease characterized by thrombocytopenia and kidney failure (Laure et al., 2013). Therefore there is a need for the new potential sources of antibiotic or concurrent use of probiotic bacteria. Another group reported that bacteriocins produced by lactic acid bacteria can treat the multidrug resistant strains (Diekema et al., 2001; Paluszak et al., 2006; Hickson, 2011). Pediococcus pentosaceus is a Gram-positive probiotic lactic acid bacteria known to produce bacteriocins and specific isolate which we have isolated from cheese - MTCC 5151 was producing a novel bacteriocin of molecular mass of 23 $\mathrm{kDa}$. Present study focuses on effect of this Lactic acid Bacteria Pediococcus on Shigella dysenteriae and reports the anti-Shigella dysenteriae activity followed by the inhibition of mammalian cellular damages caused by $S$. dysenteriae.

\section{MATERIAL AND METHODS}

\section{Bacterial strains}

Shigella dysenteriae obtained from JSS Medical College in Mysore, India was selected as a test organism. The culture was sub cultured once in 2 weeks in Brain Heart Infusion medium of $\mathrm{pH} 7.4$, and stored in the same media at $4{ }^{\circ} \mathrm{C}$. A cheese isolate, Probiotic Lactic acid Bacteria (PLB) Pediococcus pentosaceus was maintained in the laboratory as per the protocol standardized earlier in the laboratory. The culture was maintained by sub culturing in de Man Rogosa Sharpe (MRS) broth of $\mathrm{pH} 6.4$, once in 2 weeks. The cultures were confirmed by gram staining. PLB being Gram-positive stains violet while; Shigella being Gram-negative, stains pink with the crystal violet and saffranine reagents.

\section{Study of Shigella and PLB interaction}

Effect of PLB on Shigella was studied employing microscopic, electron microscopic and agar diffusion tests followed by protein profiling.

\section{Scanning electron microscopic studies}

Shigella and PLB cells were harvested after growing in their respective media, washed in Phosphate Buffered Saline (PBS), pH 7.4 (3X). $10^{5}$ cells $/ \mathrm{mL}$ of Shigella and PLB each were incubated at $37{ }^{\circ} \mathrm{C}$ for $30 \mathrm{~min}$. Respective controls for both Shigella and PLB were also maintained at similar set of experimental conditions. After the incubation, cells were fixed with $2 \%$ gluteraldehyde in PBS and processed further with alcohol treatment followed by coating with gold particles for Scanning Electron Microscopic (SEM) observation. Multiple fields of visions were viewed and documented by photography at different magnifications. Results were compared between the morphological changes in PLB as well as Shigella in their respective untreated and treated samples.

\section{Light microscopic observation}

Cell concentration about $10^{5}$ cells $/ \mathrm{mL}$ of freshly harvested and washed Shigella and PLB were incubated at $37{ }^{\circ} \mathrm{C}$ for $30 \mathrm{~min}$. Respective controls for both Shigella and PLB were maintained individually at similar set of experimental conditions. After allowing interaction between PLB and Shigella, $20 \mu \mathrm{L}$ aliquots of each were taken on to glass slides, heat fixed and processed for gram staining. Slides were observed under the light microscope and documented by photography. Effect of PLB on Shigella was monitored using differential gram staining properties between PLB and Shigella.

\section{Agar diffusion assay}

Agar diffusion assay was performed to understand the Shigella inhibitory effect of PLB. PLB was grown as described above. Lysate and the incubated media 
were collected to study their effects on Shigella growth. $10^{7}$ PLB cells $/ \mathrm{mL}$ were washed 3 times with PBS and washed PLBs were lysed by sonication; supernatant was collected after centrifugation at $2500 \mathrm{~g}$ for $15 \mathrm{~min}$ at $4{ }^{\circ} \mathrm{C}$ and the clear supernatant obtained was estimated for total protein and designated as 'PLB-Lysate (PLB-L)'. 2-3 $\mu \mathrm{g}$ protein equivalents of PLB-L and PLB-Media (PLB-M) were added to the wells ( $3 \mathrm{~mm}$ diameter) created on the $2 \% \mathrm{BHI}$ agar plate with Shigella inoculum at $10^{2}$ cells $/ \mathrm{mL}$ concentration. Ampicillin at $30 \mu \mathrm{g}$ was used as a positive control. The plate was incubated at $37{ }^{\circ} \mathrm{C}$, overnight Shigella growth inhibition was determined as the diameter of the inhibition zones around the wells. The growth inhibition diameter was an average of four measurements taken at four different directions. Efficiency of inhibition was compared with that of the known Shigella - susceptible ampicillin antibiotic.

\section{Effect of PLB lysate on growth index of Shigella}

A $10 \mu \mathrm{L}$ of $10^{7}$ cells $/ \mathrm{mL}$ was added to $1.0 \mathrm{~mL}$ of Shigella-specific media in triplicates, in presence and absence of $2 \mu \mathrm{g}$ protein equivalents of PLBLysate $/ \mathrm{mL}$. Growth index and percent growth inhibition was calculated to understand the effect of PLB lysate on Shigella growth. Growth was measured as a turbidometric measure at $\mathrm{A}_{660} \mathrm{~nm}$ in a Beckman spectrophotometer. Percentage inhibition in presence of given concentration is calculated as follows:

Growth inhibition (\%)

100 - Absorbance of Shigella culture tube with PLB lysate - Absorbance of PBS Absorbance of Shigella culture tube - Absorbance of PBS

\section{Confirmation of PLB lysate induced Shigella lysis by electrophoresis}

If Shigella is lysed by PLB lysate, Shigella proteins are expected to be released and this is studied by electrophoresis. The effect of PLB cell lysate on Shigella cells was studied comparing the protein profile data of PLB lysate and supernatant of Shigella culture with and without treatment with PLB-L. The procedure described briefly is as follows: $100 \mu \mathrm{L}$ aliquot from $10^{7}$ cells $/ \mathrm{mL}$ of Shigella culture was washed thoroughly with sterile PBS and suspended in 100 $\mu \mathrm{L}$ of sterile PBS. $50 \mu \mathrm{L}$ of this aliquot was treated with $50 \mu \mathrm{L}$ of PLB cell lysate and incubated at $37{ }^{\circ} \mathrm{C}$ for $6 \mathrm{~h}$. Respective controls of Shigella cells and PLBlysate were also maintained under similar experimental conditions. After incubation, the supernatant from all the three tubes were subjected to SDSPAGE. Proteins were stained by coomassie blue reagent and profiles were compared between PLB alone, Shigella alone and that of PLB + Shigella.

Interaction between mammalian cells and Shigella cells and its lysate

Red Blood Cells (RBCs) and Buccal Cells (BC) from humans were used during the study. The cytotoxic effects of Shigella were studied by taking in vitro models like RBC and BCs to study the protection offered by PLB against Shigella induced cellular toxicity.

\section{Effect of PLB against Shigella induced toxicity on red blood cells (RBC)}

RBCs were obtained from healthy donors after taking their consent. Heparinized blood was centrifuged at $2500 \mathrm{~g}$ for $10 \mathrm{~min}$. After removal of plasma and buffy coat, the RBCs were washed three times with Phosphate Buffered Saline (PBS $\mathrm{pH}$ 7.4) at room temperature and resuspended in PBS four times its volume for subsequent analysis. $100 \mu \mathrm{L}$ of $\mathrm{RBC}$ was incubated with $30 \mu \mathrm{L}(0.84 \mu \mathrm{g}$ of protein) of PLB cell lysate in presence of increasing amounts of Shigella cell lysate and the total volume was made up to $300 \mu \mathrm{L}$ with PBS. It was incubated at $37{ }^{\circ} \mathrm{C}$ for $20 \mathrm{~min}$ and centrifuged at $2500 \mathrm{~g}$ for $10 \mathrm{~min}$ at room temperature. Respective controls of Shigella and PLB cell lysates were maintained under similar conditions. Hemoglobin released from cells in the supernatant, due to hemolysis was diluted four times with PBS and read spectrophotometrically at $410 \mathrm{~nm}$.

\section{Effect of PLB against Shigella induced toxicity on buccal cells}

Buccal cells (BC) were isolated from human volunteers and washed with phosphate buffered saline and resuspended in minimum amount of PBS. $30 \mu \mathrm{L}$ of BC suspension $\left(1 \times 10^{4}\right.$ cells $/ \mathrm{mL}$ of PBS) were incubated for $20 \mathrm{~min}$ at room temperature with $30 \mu \mathrm{L}$ of Shigella cell lysate $(20 \mu \mathrm{g}$ of protein) or Shigella incubated media respectively. In the second set $30 \mu \mathrm{L}$ of $\mathrm{BC}$ suspension preincubated with PLB lysate or PLB incubated media was treated with Shigella lysate or Shigella incubated media were set up at similar set of experimental conditions. Treatment with either PLB cell lysate or PLB incubated media alone will serve as the control. Cells both treated and untreated were observed under the microscope upon staining with acridine orange and ethidium bromide at different magnifications. The results were documented by photography.

\section{RESULTS}

\section{Effect of Probiotic Lactic acid Bacteria on Shigella}

The effect of Probiotic Lactic acid Bacteria on Shigella was studied by performing microscopic studies, agar diffusion assay and protein profiling.

\section{Electron microscopic observation of Shigella upon treatment with PLB}

Studies with Scanning Electron Microscopy suggested that the incubation of Shigella cells (Fig. 1a) with PLB (Fig. 1b) resulted in the aggregation and condensation of cytoplasmic components of the Shigella cells which looks like a white condensed dot (Fig. 1c). Further, prolongation of incubation for $30 \mathrm{~min}$ resulted in emptying of cellular content of Shigella (Fig. 1d), while PLB remained unaffected (Arrow in Fig. 1d). Thus the result suggests that PLB may have cytotoxic effect against Shigella, a bacterial pathogen.
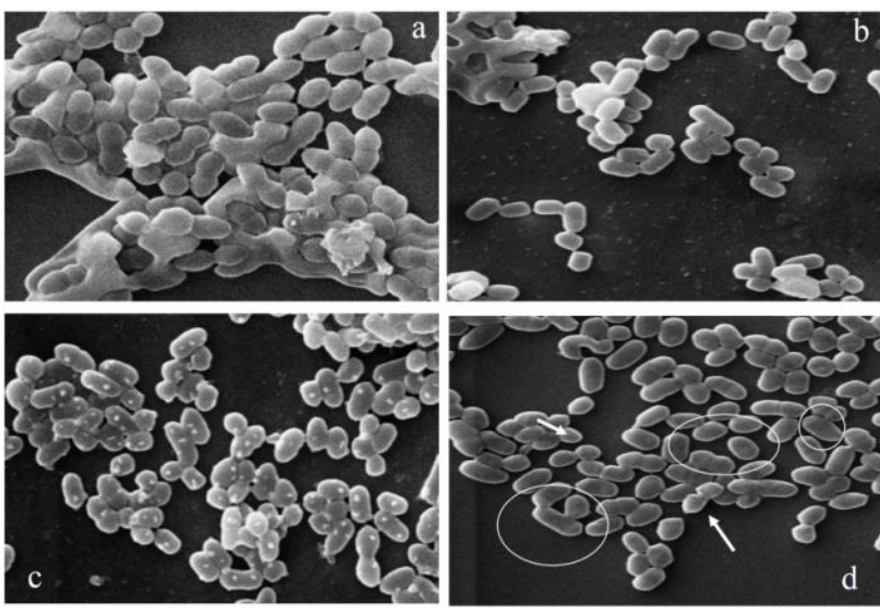

Figure 1 Photographs of scanning electron microscopic study, depicting (a) Shigella cells; (b) PLB cells; (c) Shigella incubated with PLB for $10 \mathrm{~min}$; (d) Shigella incubated with PLB for $30 \mathrm{~min}$. Elongated cells of Shigella with emptiness indicate the lysis shown in circles; Small PLB cells remained unaffected indicated by arrows.

\section{Light microscopic observation of Shigella upon treatment with PLB}

Gram staining followed by observation of untreated Shigella (Fig. 2b) and PLB (Fig. 2a) treated Shigella (Fig. 2c and Fig. 2d) in light microscopy revealed aggregation of Shigella pathogen (pink colored gram negative bacteria) with uniformly distributed PLB suggesting the attack of PLB on Shigella rather than the vice versa. Aggregation of pink Shigella cells (Fig. 2c) observed after $10 \mathrm{~min}$ of incubation, was lysed during prolonged incubation of 30 min (Fig. 2d). Data thus suggests the ability of PLB to kill Shigella.
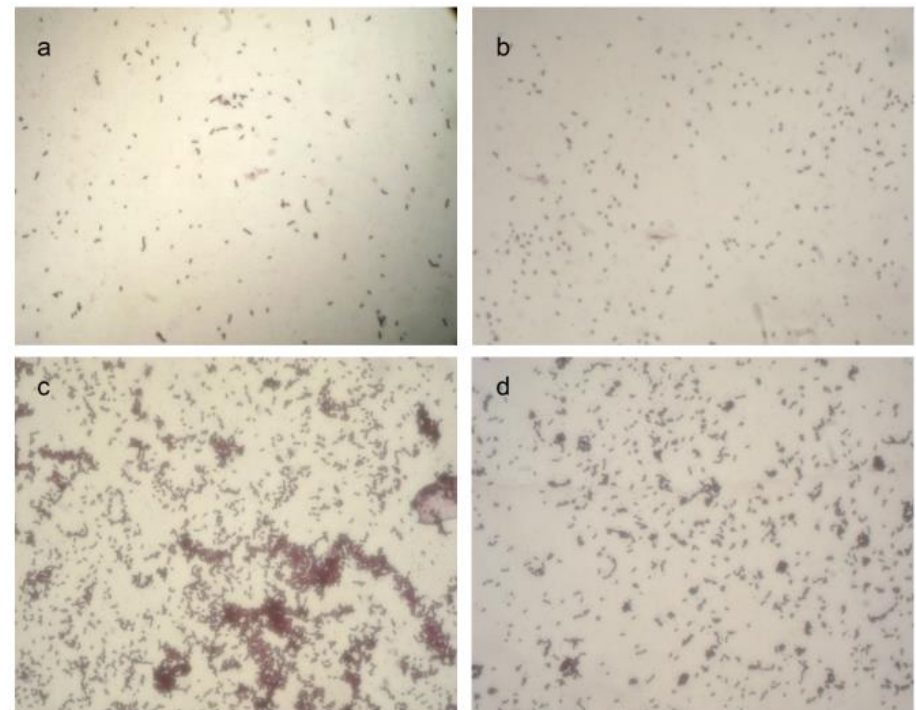

Figure 2 Photograph of Gram staining showing (a) Probiotic Lactic acid Bacteria; (b) Shigella; (c) Shigella interaction with PLB for $10 \mathrm{~min}$ at $37^{\circ} \mathrm{C}$; (d) Shigella interaction with PLB for $30 \mathrm{~min}$ at $37^{\circ} \mathrm{C}$. 
Agar diffusion assay

Agar diffusion assay showed clear growth inhibition zone of $14 \mathrm{~mm}$ diameter around the well containing PLB cell lysate at $3.5 \mu \mathrm{g}$ protein concentration (Fig. $3 \mathrm{~b}$ ) as opposed to Ampicillin (34 mm) antibiotic at a concentration of $30 \mu \mathrm{g}$ (Fig. 3a) suggesting the lysing ability of PLB against Shigella. PLB incubating media (Fig. 3c) also showed inhibitory zone, but to lesser extent which could be due to the dilution effect. Similar growth inhibition zones of Shigella by PLB was reported (Smita and Vaijayanti, 2014).

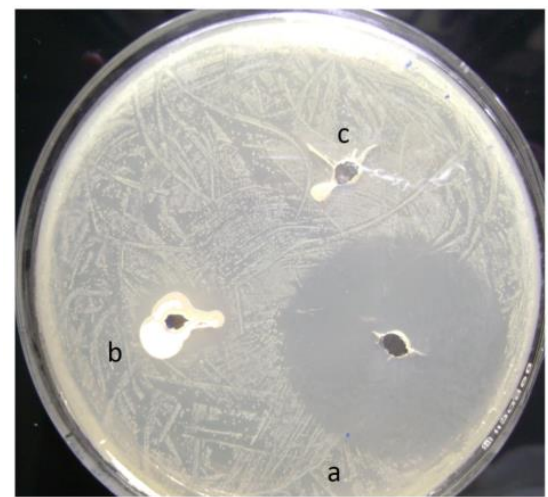

Figure 3 Agar plate showing growth inhibition zones of Shigella: (a) Ampicillin; (b) PLB cell lysate; (c) PLB incubated media. Inhibition was more with Ampicillin (34 mm) than PLB-L (14mm); than PLB-M $(<6 \mathrm{~mm})$.

\section{Effect of PLB lysate on growth index of Shigella}

Shigella cell density decreased with increase in PLB lysates protein concentration (Table 1). Quantitative study results, the percentage of Shigella inhibition by PLB lysate was depicted (Fig. 4). PLB lysate inhibited Shigella growth in the culture broth confirming the ability of PLB lysate on Shigella lysis.

Table 1 Percentage of Shigella growth inhibition by PLB lysate at varied protein concentration

\begin{tabular}{lc}
\hline $\begin{array}{l}\text { Protein concentration of PLB Lysate } \\
(\boldsymbol{\mu g} / \mathbf{m L})\end{array}$ & Shigella growth $(\boldsymbol{\%})$ \\
\hline 0 & 100 \\
20 & 95 \\
40 & 83 \\
60 & 81 \\
80 & 79 \\
\hline
\end{tabular}

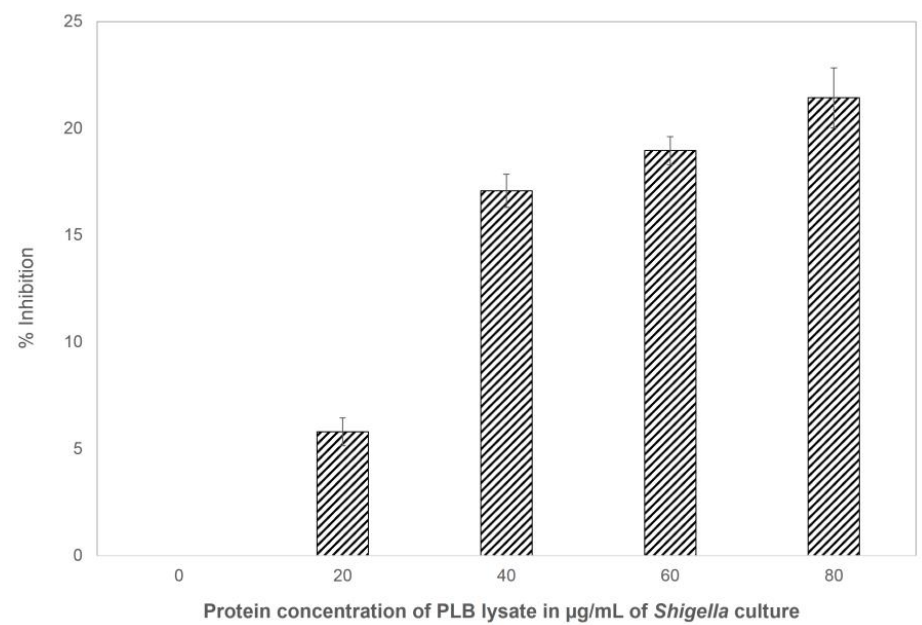

Figure 4 PLB lysate protein concentration dependent growth inhibition of Shigella.

\section{Confirmation of PLB lysate induced Shigella lysis by electrophoresis}

Results of electrophoresis (Fig. 5) showed different band pattern of proteins. The band pattern in Lane 1 represents PLB lysate, Lane 2 represents Shigella cell supernatant and Lane 3 represents the proteins in PLB lysate along with proteins released from Shigella when treated with PLB lysate which causes Shigella lysis. Differential band patterns between PLB lysate protein profile in Lane 1 and Shigella + PLB lysates protein profile in Lane 3 is due to additional proteins from Shigella lysis which confirms the capacity of PLB lysate on Shigella lysis.

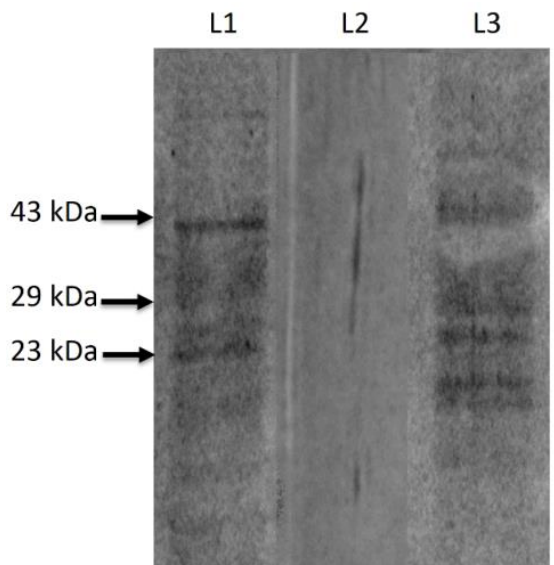

Figure 5 Gel photograph of SDS - PAGE showing protein profiles L1- PLB lysate, L2-Supernatant of Shigella cells and L3- Supernatant of Shigella cells treated with PLB lysate.

\section{Interaction of mammalian cells with PLB and Shigella}

Determination of cytoprotectivity of PLB against the cytotoxic effects of Shigella

From the above results it is proven that Shigella, a bacterial pathogen can be degraded by PLB or PLB lysate. Current experiment addresses the effect of Shigella on mammalian cells; and its effect in presence of PLB. In course the effect of Shigella lysate on human red blood cells and buccal cells were studied.

\section{Effect of PLB against Shigella induced toxicity on red blood cells (RBC)}

Data (Fig. 6) revealed that Shigella lysate lysed RBCs in a dose dependent manner. At $1.0 \mu \mathrm{g}$ protein concentration of Shigella, $100 \%$ damage was observed. However $0.8 \mu \mathrm{g}$ protein concentration of PLB protected RBCs up to $46 \%$ suggesting that PLB may offer protection against Shigella induced cellular damage.

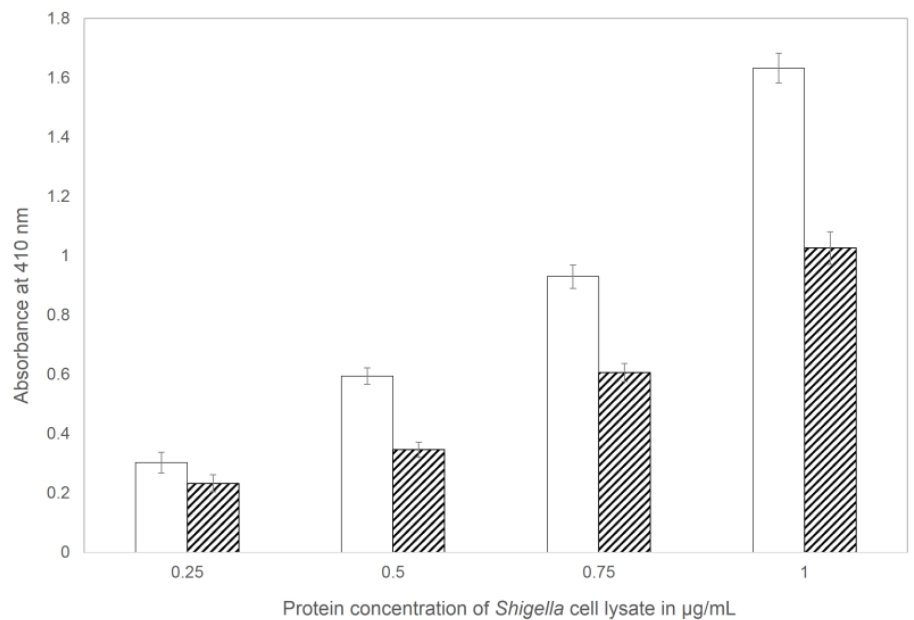

Figure 6 Effect of Shigella lysate on RBC at different concentrations with and without PLB lysate.

\section{Effect of PLB on Shigella induced effect on buccal cells}

Effect of Shigella, PLB, Shigella lysate, PLB lysate and in combination on buccal cells (BC) was studied. Results (Fig. 7) revealed that both Shigella lysate (Fig. 7c) and the Shigella (Fig. 7e) induced cytotoxicity of BC with disruption in cellular morphology when compared to that of untreated control (Fig. 7a). Buccal cells depicted in Fig. 7d and Fig. 7f shows the protection effect on buccal cells against Shigella lysate and Shigella respectively. Data thus suggests the presence of cytotoxic compound in the Shigella, which is also released into the media during the culturing as evidenced by cellular damage by the media. However, these damages could be prevented by the addition of either PLB lysate (Fig.7b) or the media (Fig. $7 \mathrm{~g}$ ) at $12 \mu \mathrm{g}$ and $3 \mu \mathrm{g}$ protein concentration respectively. PLB as such did not cause any toxicity to cells including the PLB lysate (Fig. 7b) and the PLB media (Fig. 7g). Data thus further suggests that PLB is potentially non toxic to host cells; while being toxic to the pathogenic organism - Shigella. As well PLB has the potential to protect mammalian cells against Shigella induced damages. Therefore the overall data suggests that PLB may have potential to 
prevent Shigella induced pathogenesis by either inhibiting the growth of Shigella or lysing them or neutralizing the toxins produced by Shigella.
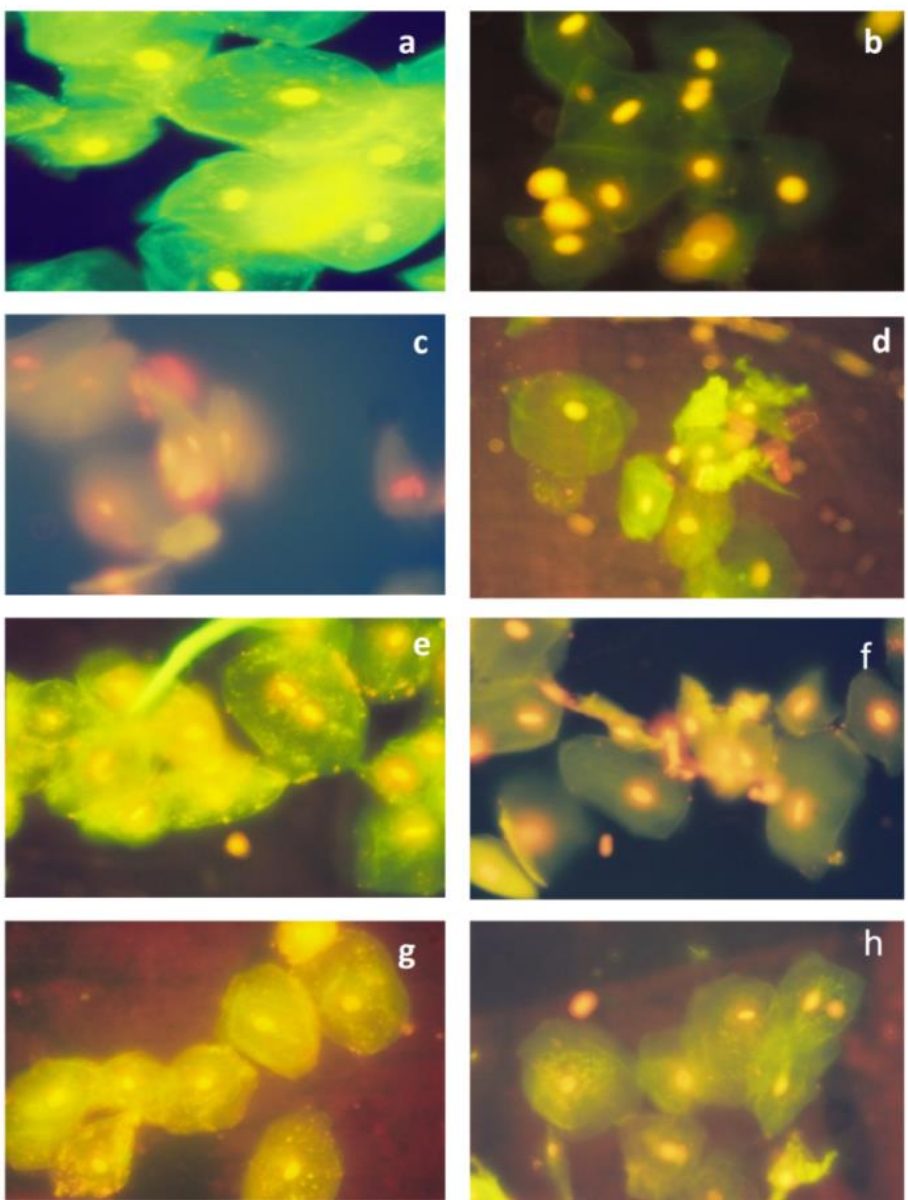

Figure 7 Effect of Shigella on buccal cells.

(a) untreated buccal cells; (b) buccal cells treated with PLB lysate; (c) bucca cells treated with Shigella lysate; (d) buccal cells treated with Shigella lysate and PLB lysate; (e) buccal cells treated with Shigella incubated media; (f) bucca cells treated with Shigella incubated media and PLB lysate; (g) buccal cells treated with PLB incubated media; (h) buccal cells treated with PLB incubated media and Shigella lysate.

\section{DISCUSSION}

Shigellosis is a bacterial infection that affects the digestive system. During Shigellosis, Shigella invades into the human intestinal mucosa, harbors there and causes dysentery, followed by recto-colitis responsible for lethal complications. Antibiotics such as azithromycin, ciprofloxacin, co-trimoxazole are often prescribed for it (Taneja, 2007). Antibiotic resistance together with the loss of gut beneficial microbes indeed enhances the severity of shigellosis complications. Prolonged and frequent shigellosis may end up with development of postinfection arthritis which include joint pain, painful urination and eye irritation Post-infection arthritis can become a chronic condition that lasts several months, years or the rest of the life.

Cultures of direct - fed microorganisms or probiotics are able to multiply in the intestinal tract to create a balance of microflora (Biradar et al., 2004). Some lactobacillus species used in probiotic applications include L. acidophilus, $L$. casei, L. reuteri, L. rhamnosus, Pediococcus pentosaceus and Bifidobacterium bidifum. Our previous study has indicated that a cheese isolate Pediococcus pentosaceus Lactic acid Bacterium (PLB) which has been deposited at the Microbial Type Culture Collection centre, Chandigarh with the accession number MTCC 5151 was effective in inhibition Shigella growth (Renu and Shylaja, 2012). In the current study we provide evidence for the anti-Shigella effect of PLB through microscopic and biochemical tests. Effective inhibition of Shigella growth by PLB was evident as per light microscopic and scanning electron microscopic studies. Formation of inhibitory zone by PLB, lysis of Shigella by PLB lysate as evidenced by electrophoresis further confirms the anti-Shigella effect of PLB and it accord with other reports (Smita and Vaijayanti, 2014). Interaction of Shigella with mammalian cells inducing cellular damages both in the red blood cells and mammalian buccal cells; inhibition of the same by PLB, supports the fact that PLB is interacting with Shigella. An anti-Shigella activity of PLB could be due to the antimicrobial property of bacteriocin as highlighted in our earlier studies (Renu and Shyalaja, 2012). Hence it confirms the Pediococcus a Probiotic Lactic acid Bacteria as a antagonist of Shigella dysenteriae, similar anti-Shigella dysenteriae activity by few other strains of lactic acid bacteria was reported (Devraj et al., 2007; Moorthy et al., 2010).

\section{CONCLUSION}

The above study indicates that the Probiotic Lactic acid Bacteria, Pediococcus pentosaceus has anti Shigella activity and it has proven that regular intake of probiotic food supplements are beneficial in enteric infections like Shigellosis.

Acknowledgments: The authors would like to thank the Director of Central Food Technological Research Institute, for providing facilities and Department of Science and Technology for funding and support.

\section{REFERENCES}

ALAM, S., SHRISH, B. 2006. Current Status of Anti-Diarrheal and AntiSecretory Drugs in the Management of Acute Childhood Diarrhea. Indian J Pediatr, 73, 693-696. http://dx.doi.org/10.1007/bf02898447

BIRADAR, S., BHAGAVATI, S., SHENGUNSHI, B. 2004. Probiotics and Antibiotics: A brief Overview. The Internet Journal of Nutrition and wellness, 2, 1-6. http://dx.doi.org/10.5580/fc0

DATTA, S., CHATTOPADHYAY, S., NAIR, G.B., ASISH, K.M., JABARANJAN, H., BERG, D.E., SAHA, D.R., KHAN, A., AMAL, S., BHATTACHARYA, S.K. AND ABHIJIT, C. 2003. Virulence Genes and Neutral DNA Markers of Helicobacter pylori Isolates from Different Ethnic Communities of West Bengal, India. Journal of Clinical Microbiology, 3737-3743. http://dx.doi.org/10.1128/jcm.41.8.3737-3743.2003.

DEEN, J., SUR, D., RAMAMURTHY, T. 2004. Shigellosis: challenges and management issues. Ind J Med Res, 120, 454-462.

DEVARAJ, S.N., MOORTHY, G., MURALI, M.R. 2007. Protective role of lactobacilli in Shigella dysenteriae induced diarrhea in rats. Nutrition, 23, 424433. http://dx.doi.org/10.1016/j.nut.2007.03.003

DIEKEMA, D.J., PFALLER, M.A., SCHMITZ, F.J. 2001. Survey of infections due to Staphylococcus sp. Frequency of occurrence and antimicrobial susceptibility of isolates collected in the United states, Canada, Latin America, Europe and the Western pacific region for the sentry antimicrobial surveillance program. Clin Infect Disease, 32, 114-132. http://dx.doi.org/10.1097/00019048200106000-00032

HICKSON, M. 2011. Probiotics in the prevention of antibiotic-associated diarrhea and Clostridium difficile infection. Therapeutic Advances in Gastroenterology, 4, 185-197. http://dx.doi.org/10.1177/1756283x11399115

LAURE, B.M.K., JOSEPH, L.T., JACQUES, K. 2013. The anti-shigellosis activity of the methanol extract of Picralima nitida on Shigella dysenteriae type I induced diarrhea in rats. BMC Complementary and Alternative Medicine, 13 211-222.

http://dx.doi.org/10.1186/1472-6882-13-211

MOORTHY, G., MURALI, M.R., DEVARAJ, S.N. 2010. Lactobacilli inhibit Shigella dysenteriae-1 induced pro-inflammatory response and cytotoxicity in host cells via impediment of Shigella-host interactions. Digestive and Liver Disease, 42, 33-39. http://dx.doi.org/10.1016/j.dld.2009.04.021

PALUSZAK, Z., JUSTYNA, B.K., BEATA, S. 2006. Inhibitory effect of Lactic acid bacteria of genus Lactobacillus on the survival of Proteus and Shigella rods in mixed cultures. Bull Vet Inst Pulaway, 50, 335-340.

REEMA, N., LAHARI, S., GARGI, C., DAISY, S. 2013. Drug resistant Shigella flexneri in \& around Dibrugarh, north-east India. Indian J Med Res, 137, 183 186.

RENU, A., SHYLAJA, D. 2012. An anti-Shigella dysenteriae bacteriocin from Pediococcus pentosaceus MTCC 5151 cheese isolate. Turk J Biol, 36, 177-185.

SMITA, N., VAIJAYANTI, S. 2014. Evaluation of antimicrobial activity of probiotic microflora from neonatal origin. Asian Journal of Multidisciplinary Studies, 2, 182-283.

SWAPAN, K.N. 2005. Shigellosis. The Journal of Microbiology, 43, 133-143.

TANEJA, N. 2007. Changing epidemiology of shigellosis and emergence of ciprofloxacin resistant Shigellae in India. J Clin Microbiol, 45, 678-679. http://dx.doi.org/10.1128/jcm.02247-06 